\title{
Deaf mis-interpretation during Hurricane Irma: A case study and evaluation
}

\author{
Sherilyn D. Burris \\ Cascia Consulting LLC \\ Sarasota, Florida USA
}

\begin{abstract}
In 2017, Manatee County Government (Florida, USA) used an untrained sign language interpreter during a media briefing on Hurricane Irma evacuation orders. The individual signed incorrectly, resulting in confusion for the community and embarrassment for the organization. This case study presents the background of accessible information in crisis management -- why and how disaster preparedness information is interpreted for the deaf community; provides the event's consequences, as well as local and global implications; and discusses ways to incorporate deaf and hard-of-hearing stakeholders and groups into existing structures and programs.
\end{abstract}

Keywords - American Sign Language, Crisis Communications, Deaf Interpreter, Emergency Management, Hurricane

SUGGESTED CITATION: Burris, S. D. (2019). Deaf mis-interpretation during Hurricane Irma: A case study and evaluation. Proceedings of the International Crisis and Risk Communication Conference, Volume 2 (pp. 9-11). Orlando Fl: Nicholson School of Communication and Media. https://doi.org/10.30658/icrcc.2019.2

\section{INTRODUCTION}

Hurricane Irma was forecast to impact Manatee County, Florida, requiring storm surge evacuation orders for over 100,000 residents. On September 8, 2017, the agency issued hurricane evacuation orders during a live press conference and using Facebook live - a social media platform serving live video on the networking site. An untrained employee volunteered to provide sign language interpretation. The employee used home sign, resulting in incorrect interpretations of most of the spoken press conference. This case study explores the impacts of the event, as well as systemic issues behind emergency management programs' failure to provide accessible and inclusive information to the deaf and hard of hearing communities and to other groups broadly considered to be non-traditional audiences.

\section{METHODOLOGY}

This case study is based on the author's first-person account and naturalistic observation of the event, as Incident Commander of the county's emergency management agency and oversight of many disaster-related activities, including issuing the hurricane evacuation orders and providing messages for media dissemination.

\section{CASE PRESENTATION}

Hurricanes create a variety of hazards to people and property. Local government officials issue hurricane evacuation orders to protect people from deadly storm surge, and provide emergency sheltering against tropical storm and hurricaneforce winds. These hurricane evacuation orders are generally provided via reverse 911 system for subscribers and through traditional and social media -- including written statements. Government agencies must communicate these instructions clearly, reaching everyone at risk. Instructions may often be additionally communicated in Spanish and written text, and distributed through unique media platforms. Local agencies must include information in alternate formats in accordance with the Americans with Disabilities Act to ensure communication with all at risk by providing closed captions and video transcripts. Of note, the Rehabilitation Act of 1973 was extended to apply to online video content (i.e., online videos, such as Facebook Live or YouTube videos). At the time of the press conference, Hurricane Irma was forecast to make landfall in Manatee County as a strong Category 4 storm. Due to the Hurricane Irma's extreme potential impact as disaster of national concern, the press conference brought national media attention and backlash. Hurricane Harvey had recently brought devastation to Texas, which only increased Florida's media attention in Hurricane Irma.

ISSN: 2576-9111

(C) 2019 Copyright is held by the owner/author(s).

Publication rights are licensed to ICRCC.

https://doi.org/10.30658/icrcc.2019.2 
As Hurricane Irma threatened Florida's southwest coast, Manatee County's local emergency management agency issued hurricane evacuation orders and public safety information during a live press conference. Prior to September 2017, Manatee County Government did not use American sign language interpretive services during live events or for videos posted online. The agency did not have a sign language interpreter able to fulfill disaster work - the requirements to stay within the emergency operations center for the duration of the event, often working 18-hour shifts, and without the ability to bring parents, pets, or children into the center. An agency employee volunteered to provide sign language interpreting based on his ability to communicate with his deaf brother. The press conference information was relayed using the volunteer. The interpreter failed to communicate the information, used incorrect signs, and signed gibberish instead of the information being orally relayed during the press conference. The agency employee used home sign - an informal communication method often used at home by families of deaf children. Once the agency realized the interpreter's shortcomings, he was not used again for sign language translation. The misinterpretation of public safety information has the potential to lead to injury, illness, or death. Without any other access to information, deaf and hard of hearing individuals would not be aware of or understand the evacuation orders. Deaf and hard of hearing populations in the local evacuation area could have not received the message to evacuate. If a person did not evacuate, they could have been injured or killed by the storm surge.

\section{OUTCOMES}

Populations in the local area received and acted upon evacuation messages in multiple formats across multiple platforms. The local message was distributed internationally. Deaf and hard of hearing populations around the world became angry and upset about the event. Almost as soon as the press conference concluded, people began calling into the county's information hotline with complaints, and sending emails and social media messages to the agency regarding the interpreter, expressing anger and concern. The messages came from not only county residents but largely from individuals not living in or near the jurisdiction. Additional calls to the hotline increased the workload on the employees, who were not prepared to respond to such calls. The increased workload detracted from the mission to provide information to county residents and employees still responding to the disaster. The event and subsequent community complaints was replayed online, captured in print media, on broadcast television news, and also on an American late-night talk and news satire television program, The Daily Show with Trevor Noah. The news coverage negatively impacted staff morale and the agency's reputation, which was seen as insensitive or incompetent. Following the storm and the end of hurricane season, the agency sought a contractual agreement with a trained sign language interpreter service able to fulfill emergency and disaster needs.

\section{SYSTEMIC AND CULTURAL ISSUES}

Emergency management considers deaf and hard of hearing as special needs. In guidance and accreditation documents, special needs are needs that are not fully addressed by traditional service providers. However, traditional service provider is not further defined. The lack of explicit federal requirements for the provision of emergency management information in alternate formats may result in misinformation to deaf and hard of hearing individuals. Local government emergency management agencies are not required to provide participatory development of programs targeting disability groups. Meaning, emergency managers develop programs to reach their local deaf and hard of hearing communities without assessing their needs or surveying their resources. Manatee County outlined their special needs program, which included a committee of mostly healthcare partners and government employees but did not include representatives of the target audience. Without deaf and hard of hearing residents on the committee, government employees did not understand their needs, and these needs were not included in the agency's activities.

\section{CONCLUSION}

Life safety during natural hazards requires public safety agencies to provide correct information to each individual within the agency's jurisdiction. As disasters following natural hazards grow in frequency and severity, emergency managers' room for communication error decreases. Without positive intervention, the threat of misinterpretation will continue to grow. Repetitive events - violations of the Americans with Disabilities Act (ADA) and others - will additionally degrade public trust in government. The lack of federal requirements tolerate, even encourage local governments to not meet the needs of the whole community. Current federal government emergency management guidelines fail to address disability inclusion in planning phases in which messages and communication methods are developed and tested. Creating accessible information is treated as a secondary activity, and usually only if requested by a resident through the agency disability coordinator. Information accessibility is treated as an as-needed, after-the-fact activity. There was no dedicated accessibility oversight and coordination disaster role. Deaf and hard of hearing populations are vulnerable because emergency management programs do not cater to them -- not in spite of. Disability communities are treated as a separate program requirement, above the minimum program scope, detracting away from program resources and requiring additional resources. All people, regardless of ability or capacity, need information in a disaster. This is not a special or unique need to one particular group of people. The first step to address the exile of deaf and hard of hearing needs as a post-script or after-the-fact activity. Federal policy must eliminate inclusive and accessible programs as being additional, beyond 
traditional scope, or special. Emergency management programs should treat all needs as part of their traditional services and program. Government must move to require accessibility officers and ADA Coordinators to participate in disaster program activities. This dedicated position must review, evaluate, and champion inclusive and accessible activities before, during, and after a disaster as part of the agency leadership team.

\section{Author Biography}

Sherilyn D. Burris, received a Master of Public Administration and Emergency Management from Jacksonville State University; and is a Consultant and Advisor with Cascia Consulting LLC. She can be reached at sherilyn@casciaconsulting.com 